\title{
MODIFICATION OF THE ELECTRODE PITCH OPERATIONAL PROPERTIES
}

\author{
Anatoly Starovoyt ${ }^{1}{ }^{凶}$, Evgeniy Malyi ${ }^{1}$, Michael Chemerinskii ${ }^{1}$, \\ Anatoly Timoshenko ${ }^{1}$
}

https://doi.org/10.23939/chcht15.03.450

\begin{abstract}
In this work, the influence of the carbon modifier type and its amount on the processes of carbonization of the electrode pitch and carbon masses for carbon production was investigated experimentally. The paper presents the processes that occur during the carbonization of the electrode pitch and the change in its properties during the modification process. It is shown that the most promising additive is a medium-boiling polymer mixture, which contributes to the carbonization of pitch and improves the physico-chemical properties.
\end{abstract}

Keywords: carbonization, electrode pitch, carbon mass, graphitosomal supramolecular structures.

\section{Introduction}

The electrode pitch is a complex heterogeneous system consisting of carbo- and heterocyclic compounds and their compaction products, used as a binder and impregnating agent in electrode production.

In electrode production, the constancy of the main technological characteristics of the electrode pitch is of great importance, which was noted in [1-3]. Currently, researchers have found $[4,5]$ that the electrode pitch obtained at the stage of single evaporation of coal tar, without additional heat treatment, can not be used as a material for electrode products. It was established that the main reason is the relatively low yield of coke residue and insignificant content of group components ( $\alpha_{2}-$ and $\beta$-fractions), which provide relatively good carbonization $[6,7]$.

We set a goal to improve the performance of pitch in relation to solid carbon materials, which best characterizes its quality and this lead to the investigation of various plasticizing additives of organic origin $[8,9]$.

As a rule, the plasticization effect is associated with the ability of low molecular weight substances to change

\footnotetext{
${ }^{1}$ National Metallurgical Academy of Ukraine,

4, Gagarina Ave., 49600 Dnipro, Ukraine

凶netau_mtv@i.ua

(C) Starovoyt A., Malyi E., Chemerinskii M., Timoshenko A., 2021
}

the internal energy of the pitch system, affecting the phase boundary. Therefore, organic substances of aromatic composition were tested as plasticizers: benzene acid tar and washed phenolic fraction [10,11].

The practical value of the modification is reflected in the works [1-14], which are devoted to the issues of destruction and carbonization, where the processes occurring during thermal pyrolysis of pitch are considered as a chain of parallel-sequential reactions, the essence of which is irreversible destruction reactions, constituting fragments of pitch in the form of graphitosomal formations and the synthesis on this basis of new chemical compounds.

Having considered this, it is very important to establish the effect of organic substances as modifiers for electrode pitch. Insufficient study of the organic substances effect on the performance properties of electrode pitch determined the direction of researches: effect of modifiers on carbonization process and yield of coke residue from pitch and their complex characteristics.

\section{Experimental}

The electrode pitch brand B (Table 1) and modifiers were used as the materials for this study. The modifiers were model mixtures of the following composition:

- Carbon-containing polymer mixture (CCP), composed of (wt \%): coal tar 31.50; the carbon particles 68.50 ;

- Light boiling polymer mixture (LBP), composed of (wt \%): benzene-styrene copolymer 3.96 ; thiophene dimer 20.37; thiophene-styrene copolymer 9.40; toluenestyrene copolymer 19.20; xylene-styrene copolymer 22.80; styrene dimer 9.98; copolymer thiophene-indene 6.09; benzene-indene copolymer 1.09 and naphthalene 7.47 .

- Medium boiling polymer mixture (MBP), composed of (wt \%): acetophen $0.21 ; \alpha$-methylnaphthalene 0.89 ; dimethylnaphthalene 6.00; acenaphthene 17.51; diphenylene oxide 21.00; fluorene 21.00 and resin 31.00 . 
Modifiers were introduced into the electrode pitch in the amount of 2, 4, 6 and $8 \mathrm{wt} \%$.

The softening temperature of the pitch was determined using a "ring and ball" device: the pitch was pressed into a metal ring, heated to a plastic state and the sample was deformed under the pressure of the ball (of a certain mass). The softening temperature was the temperature at which the pitch of the pitch sample was deformed (Table 1).

Table 1

\section{Characteristics of electrode pitch brand B}

\begin{tabular}{|l|c|}
\hline \multicolumn{1}{|c|}{ Index } & Value \\
\hline Softening temperature, K & 340.0 \\
\hline Yield of volatile substances, \% & 58.0 \\
\hline Ash content, \% & 0.3 \\
\hline Mass fraction of substances insoluble & 31.0 \\
in, $\% \quad$ toluene & 7.0 \\
quinoline & \\
\hline
\end{tabular}

The yield of volatile substances in the electrode furnaces is set by holding them in a muffle furnace at a temperature of $1073 \mathrm{~K}$, using a rectangular porcelain crucible with a lid for $10 \mathrm{~min}$. The yield of volatile substances in the pitch $(x, \%)$ is calculated by formula (1):

$$
x=\frac{(a-b) \cdot 100}{a}
$$

where $a$ is a prototype, $\mathrm{g} ; b$ is a residue in the crucible after heating, $g$.

The ash content $(A$, wt \%) is determined by calcination of the electrode pitch sample in a rectangular crucible at a temperature of $1073 \mathrm{~K}$ in an air stream. The calculation is performed according to formula (2) and converted to an anhydrous particle according to formula (3).

$$
B=\frac{c}{d} \cdot 100
$$

where $c$ is the mass of the obtained ash residue, $\mathrm{g} ; d$ is a prototype, $\mathrm{g}$.

$$
e=\frac{B}{100-W} \cdot 100 \%
$$

where $e$ is an ash content relative to anhydrous pitch, wt $\% ; W$ is a moisture content relative to pitch, wt $\%$.

The arithmetic mean of two parallel experimental values is taken (Table 1 ).

The mass fraction of substances insoluble in toluene or quinoline is determined by dissolving the electrode pitch sample in the appropriate chemical and filtering through a filter. The content of substances insoluble in the corresponding chemical solvent $(y, \%)$ is calculated by formula (4):

$$
y=\frac{(k-m) \cdot 100}{c}-x
$$

where $k$ is the mass of the beaker with filters and sediment, $\mathrm{g} ; m$ is the mass of the beaker with filters before analysis, $\mathrm{g} ; c$ is the pitch sample, $\mathrm{g}$; $x$ is the percentage of ash in the pitch, $\%$.

The discrepancy between the results of two parallel tests should not exceed $0.8 \%$.

Studies of carbonization of the electrode pitch were performed according to the method developed by us: the pitch is heated to a temperature of $403 \mathrm{~K}$, and then loaded into a steel cylinder, which has an upper diameter of 58 $62 \mathrm{~mm}$, lower diameter of $68-72 \mathrm{~mm}$ and a height of $250 \mathrm{~mm}$. Roasting is carried out in a muffle furnace according to the following instructions. The first two hours the temperature is raised to $373 \mathrm{~K}$, then to $1173 \mathrm{~K}$ at a rate of $100 \mathrm{~K} / \mathrm{h}$ with the exposure to the final temperature for three hours. A sample of $60 \times 60 \mathrm{~mm}$ is cut from the carbonized pitch and analyzed.

Determination of compressive strength $\left(\sigma_{c s}\right)$ and fracture $\left(\sigma_{r}\right)$. The method of analysis is based on the study of samples to withstand different loads, which is determined by formulas (5) and (6).

$$
\sigma_{c s}=\frac{P}{S}
$$

where $\sigma_{c s}$ is an ultimate compressive strength, $\mathrm{MPa} P$ is a breaking load, N; $S$ is a cross-sectional area of the sample, $\mathrm{mm}^{2}$.

$$
\sigma_{r}=0.713\left(\frac{P}{d h}\right)+0.52
$$

where $\sigma_{r}$ is a tensile strength, $\mathrm{MPa} ; P$ is a breaking load, $\mathrm{N}$; $d$ is a sample diameter, $\mathrm{mm}$; $h$ is a sample height, $\mathrm{mm}$; 0.52 is the coefficient taking into account the structure of the material; 0.713 is the correction factor.

The arithmetic mean according to the formula (7) is taken as the result of the research.

$$
\sigma_{r(c s)}=\frac{1}{n} \sum_{i=1}^{n} \frac{P}{\sigma_{i}}
$$

where $\sigma_{i}$ is a tensile strength of the first sample, MPa; $n$ is a number of the samples.

The resistivity $(\rho, \mathrm{Ohm} \cdot \mathrm{m})$ was determined as following: the sample was placed between two probes and a voltage was applied; it was measured at a specific area, which is then calculated by formula (8).

$$
\rho=\frac{U \cdot S}{I \cdot l}
$$

where $U$ the difference in electrical potentials (voltage) at the ends of the conductor, $\mathrm{V} ; S$ is the cross-sectional area of the sample, $\mathrm{m}^{2} ; I$ is the current flowing between the ends of the conductor under the action of a potential difference, $\mathrm{A} ; l$ sample height, $\mathrm{m}$. 
To determine the porosity $(P, \%)$ of the samples, the analysis of the actual $\left(d_{a}\right)$ and apparent density $\left(d_{i}\right)$ was performed. The method of determining the actual density was based on the study of the sample $(2 \mathrm{~g})$, which was loaded into the pycnometer, wherein no oxygen due to boiling alcohol. The specific gravity was found by dividing the mass of the cubes $(40 \times 40 \times 40 \mathrm{~mm})$ by their volume. Several parallel determinations were performed for each sample. The porosity of the samples was calculated by formula (9).

$$
P=\frac{\left[\left(d_{a}-d_{i}\right)\right]}{d_{a}} \cdot 100
$$

Scanning electron microscopy (SEM) was performed on a Jeol JSM 840 scanning electron microscope. In a typical microscope, the image of the experimental object was formed by scanning its surface focused to $5-10 \mathrm{~nm}$ in an electron beam. This beam is called an electronic probe. When electrons interact with the surface of the experimental material, a number of complex processes take place, which lead to the appearance of radiation of different nature. Primary and secondary electrons are used to form the surface pattern. The generated signals are amplified by special devices, and then used to modulate the image in the cathode ray tube, the scan of which is synchronous with the shift of the electron probe, which is the image of the surface in the SEM.

Complex thermal analysis was performed using derivatography on the D-1500 apparatus (MOM company, Hungary) in an argon atmosphere in the temperature range of $293-1073 \mathrm{~K}$ with a heat rate of $1 \mathrm{~K} / \mathrm{min}$. The portion was $50 \mathrm{mg}$. The standard was alumina.

\section{Results and Discussion}

To study the effect of the modifiers properties on the thermochemical processes occurring during the carbonization of coal pitch, three mixtures were used according to their properties modeling different aromatic modifiers: CCP is a mixture with a high content of carbon particles and a high yield of coke residue, LBP is a mixture of aromatic hydrocarbons with the reduced polymerization ability and MBP is a polymer mixture that occupies an intermediate value by its properties.

Studies of changes in the electrode mediumtemperature pitch brand $\mathrm{B}$ in the process of cocarbonization with polymer mixtures in the temperature range of $723-773 \mathrm{~K}$ were performed using a scanning electron microscope. The sections of the original coal pitch brand B and its modifications are shown in Fig. 1.

The microstructure of the studied samples consists of sections of the solid phase and the binder mass. Sections of the solid phase are spheroids - supramolecular substances with a size of 1.5-3.5 microns. The binder mass consists mainly of colorless, tightly contacting microparticles.

Carbonization of coal tar pitch with addition of CCP is accompanied by the formation of highly condensed carbon compounds of carbenes and carbides. Penetrating the entire dispersion medium, these structural elements act as active centers capable of concentrating the higher molecular part of pitch macromolecules around themselves, forming a coagulation complex. The interaction of the pitch and the solid phase of CCP is reminiscent of the usual act of filling the polymer. A large concentration of the solid phase leads to a significant increase in the viscosity of the pitch system and its dispersion.

The interaction of MBP with the coal tar pitch is characterized by the fact that aromatic compounds with a lower molecular weight contribute to more favorable conditions for the growth of liquid crystals $>3.5 \mu \mathrm{m}$. In this case, a liquid medium is formed that provides necessary conditions for the movement of large molecules and the implementation of molecular diffusion and convection mass transfer.

The presence of branched heterocyclic bonds in LBP is accompanied by the initiation of condensation due to the formation of free radicals. Radicals can form peroxide compounds, bonds of which are weaker than usual ones, and therefore they burst at the initial stage of thermal destruction, which promotes the growth of pitch supramolecular structures. The thermal destruction products of the latter can be characterized as fractions: the most volatile fraction (occluded gases and carbon oxides); volatile fraction at a temperature of $\sim 373 \mathrm{~K}$ (toluene, xylene and methyl derivatives monomers); non-volatile fraction (macromolecules).

The results of the studies showed that the introduction of CCP in the amount of $6 \mathrm{wt} \%$ significantly affects the carbonization process, since the so-called "inert" substances, which include pyrocarbon, ash and non-melting substances, with a $\mathrm{C} / \mathrm{H}$ ratio of $\sim 20-30$, do not form plastic phases and have a negative effect on the development of graphite-like formations. MBP and LBP by the nature of their influence can be divided into plasticizing and chemically active substances.

According to the general theory of thermal degradation of polymer systems, the influence of the "dominant partner" can manifest itself at all thermochemical stages of carbonization of coal tar pitch. The process was carried out using the derivatographic method of analysis in an inert medium of argon (Fig. 2).

An analysis of the data obtained made it possible to establish the presence of three main stages of thermochemical transformations for all of the investigated pitches: transition from a fluid to a viscous-fluid state, accompanied by the energy absorption and its expenditure on increasing thermal vibrations of pitch macromolecules; inter- and intramolecular rearrangements of molecules. 


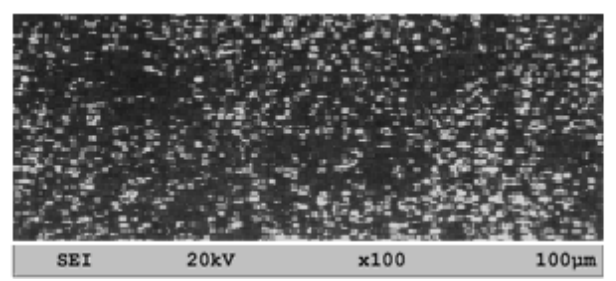

a)

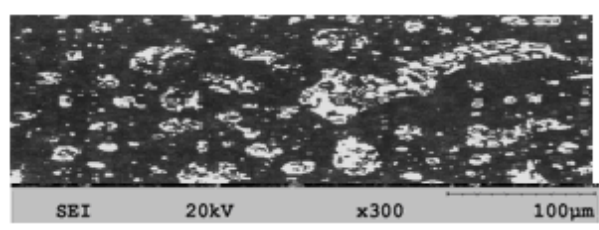

c)

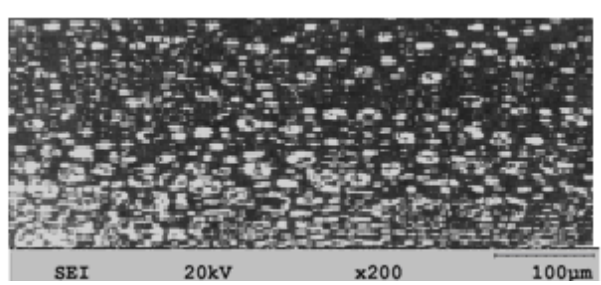

b)

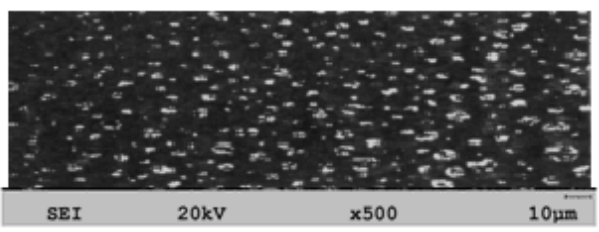

d)

Fig. 1. Microstructures of samples after heat treatment at $773 \mathrm{~K}$ of pitch $\mathrm{B}$ (a) and samples modified with CCP (b), MBP (c) and LBP (d)

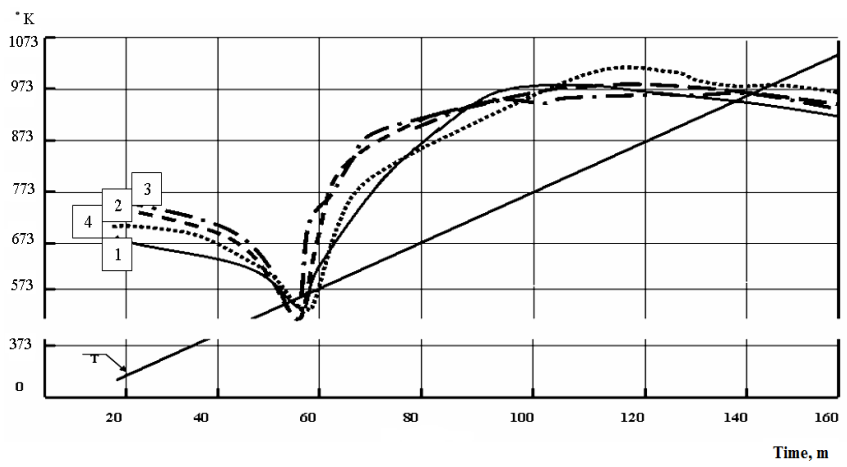

Fig. 2. Thermograms of thermal effects (DTA) of electrode pitch without additives (1) and pitches modified with $6 \mathrm{wt} \%$ of MBP (2), LBP (3) and CCP (4)

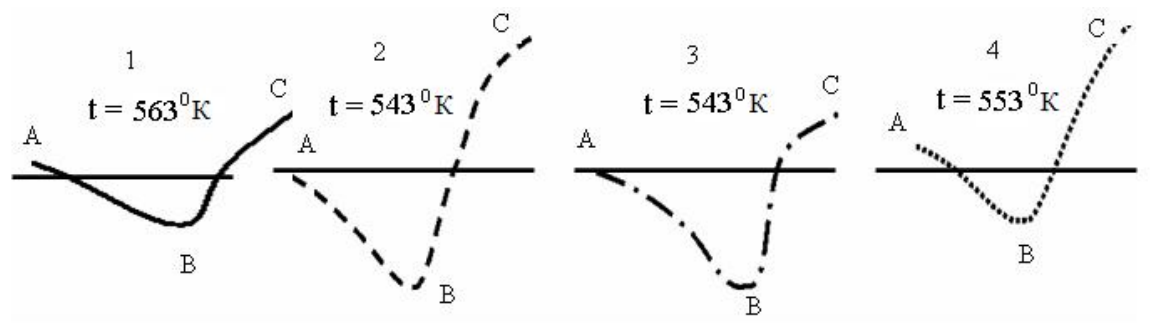

Fig. 3. Endothermic effects of the DTA curve of pitch without additives (1) and pitches modified with $6 \mathrm{wt} \%$ of MBP (2), LBP (3) and CCP (4)

Table 3

Thermographic characteristics of pitch carbonization

\begin{tabular}{|c|c|c|c|c|c|c|c|}
\hline \multirow{2}{*}{ Pitch } & \multicolumn{3}{|c|}{ Temperature range, ${ }^{\circ} \mathrm{K}$} & \multicolumn{3}{|c|}{ Mass loss rate, \% } & The total mass \\
\cline { 2 - 7 } & I & II & III & I & II & III & loss, \% \\
\hline Electrode pitch brand B & $403-523$ & $523-738$ & $738-813$ & 5.00 & 41.55 & 6.50 & 53.05 \\
\hline Pitch modified with 6 wt \% of MBP & $393-523$ & $523-738$ & $738-803$ & 5.55 & 41.45 & 6.05 & 53.05 \\
\hline Pitch modified with 6 wt \% of LBP & $413-528$ & $528-748$ & $748-813$ & 5.05 & 40.64 & 6.50 & 52.19 \\
\hline Pitch modified with 6 wt \% of CCP & $388-518$ & $553-733$ & $733-803$ & 6.11 & 43.96 & 6.98 & 57.05 \\
\hline
\end{tabular}


Energy-intensive processes directly relate to the formation of supramolecular systems - mesogens; association (coalescence) of the system. The processes are accompanied by the release of excess heat during polycondensation reactions with the formation of thermodynamically more favorable structures. Significant changes in the thermographic curves of the pitch are manifested in the second section with the addition of CCP.

Just to clarify, the sections of the endothermic effects of DTA (ABC) curves are represented in Fig. 3, a comparative analysis of which shows that the studied samples absorb a different amount of energy for the formation of mesogenic molecules. It is known that the thermal effect of thermal destruction is equal to the activation energy of broken chemical bonds and the magnitude of the endothermic effect is directly proportional to the quantity and quality of broken chemical bonds. Therefore, the more energy is absorbed at this stage, the deeper are the processes of reconstruction and the resulting pitch will have more mesogenic properties. The most energy-intensive samples are pitch samples modified with MBP and LBP (Table 3).

Apparently, the effect of additives in the amount of $6 \mathrm{wt} \%$ initiates the formation of a more perfect anisotropic structure at the second stage of thermochemical transformations. However, pitch samples with LBP are accompanied by significant mass loss $(60 \%)$, which is due to a sharp increase in the viscosity of the system and inhibition of association processes.

The coincidence of the formation temperatures of the initial structure of the viscous-fluid mass of the pitch and the MBP creates the condition for their active interaction (mass loss was $53.05 \%$ ). Here, due to the development of substitution reactions, recombination of intermediate mesogenic structures occurs. The presence of various functional groups in the MBP significantly affects the rate of thermochemical transformations and leads to a change in intermolecular rearrangements, which is manifested in a change in the surface activity of the pitch during its carbonization.

A sample of CCP pitch has the smallest mass loss $(52.19 \%)$, and a slight endothermic effect indicates that processes accompanied by the heat absorption necessary for breaking chemical bonds proceed at a lower rate. This confirms that the modified pitch is less prepared for the formation of anisotropic structures.

Comparing the thermograms of the pitch with $\mathrm{CCP}$, it is possible to note the identity of the nature of the rise of the section of the DTA (ABC) curve, as well as a closeness of mass loss values. Apparently, it is a coal tar that causes the formation of a structure characterized by an increased content of ordered fragments, which ensures the formation of a reaction medium for the creation of graphitosomal molecules.

The maxima of the exothermic peaks - the third portion of the thermogram (III temperature range) practically coincide for all the studied samples. Therefore, it can be assumed that mesophase transformations complete at a temperature of $\sim 808 \mathrm{~K}$.

The formation of liquid crystalline structures in the studied CCP pitches was stopped earlier, since the particles of the $\alpha_{1}$-fraction create spherical difficulties not only for the coalescence of the formed graphitosome spheres, but also for the development of association processes leading to the nucleation of graphite globule spheres. In pitch with LBP, the reduction in the formation time of liquid crystal structures is associated with the intensive mass loss and, consequently, with a sharp increase in the viscosity of the system.

The analysis of the average score shows (Table 4) that the microstructure of cokes from modified MBP pitches has a higher score according to anisotropy, and the introduction of other modifiers has a negative effect on the structure of the samples.

Optical microstructure of prototypes

\begin{tabular}{|c|c|c|c|}
\hline Coke residue & Temperature, $\mathrm{K}$ & Amount of additive, wt $\%$ & Carbon fiber size, $\mu \mathrm{m}$ \\
\hline Brand "B" & & - & 2.6 \\
\hline Modified MBP & & $\begin{array}{l}2 \\
4 \\
6 \\
8\end{array}$ & $\begin{array}{l}2.7 \\
2.8 \\
2.7 \\
2.5\end{array}$ \\
\hline Modified LBP & 773 & $\begin{array}{l}2 \\
4 \\
6 \\
8\end{array}$ & $\begin{array}{l}2.5 \\
2.4 \\
2.4 \\
2.0\end{array}$ \\
\hline Modified CCP & & $\begin{array}{l}2 \\
4 \\
6 \\
8 \\
\end{array}$ & $\begin{array}{l}2.5 \\
2.5 \\
2.4 \\
2.0\end{array}$ \\
\hline
\end{tabular}


The average score of the microstructure of cokes from the pitch of modified MBP with the addition of 2$4 \mathrm{wt} \%$ is in the range of 2.7-2.8 units, which indicates an improvement in the quality of anisotropy with increasing amount of MBP additive. However, the introduction of $8 \mathrm{wt} \%$ of MBP into the pitch system contributes to the return of the anisotropy of the test samples to the basic pitch coke, which is due to the low rate of its microstructure. In addition to the microstructure of the obtained cokes, their performance characteristics were also determined: density, resistivity, porosity and reactivity. To this end, a comprehensive analysis of coke samples was performed, the results of which are shown in Table 5.

Analysis of the obtained data showed that the introduction of $8 \mathrm{wt} \%$ of $\mathrm{BBC}$ in the pitch accompanies the achievement of the maximum density of experimental cokes. For example, the reactivity and electrical resistivity depend on the amount of $\alpha$-fraction, which promotes the growth of crystallization centers and the increase in the amount of quinoline-insoluble substances. A similar phenomenon can occur in our case, due to the increase in the content of aromatic hydrocarbons in the plastic mass of pitch, mesogenic macromolecules are formed, which in the process of carbonization negatively affect its performance properties.

In the case of the MBP modified pitch, the optimal result is achieved with the introduction of $4 \mathrm{wt} \%$ of additive. A further increase in the MBP content contributes to the intensification of the vapor-gas phase formation from the pitch, which leads to the formation of a porous structure of the coke residue and is reflected in a decrease of the test sample density. This is confirmed by the data obtained in the course of our research. The porosity of the modified pitch coke with $8 \mathrm{wt} \%$ of MBP reaches $60.2 \%$, and the density is at the level of $755 \mathrm{~kg} / \mathrm{m}^{3}$.

Table 5

Physico-chemical properties of coke residues from experimental pitch

\begin{tabular}{|c|c|c|c|c|}
\hline Coke residue from pitch & Density, $\mathrm{kg} / \mathrm{m}^{3}$ & Total porosity, $\%$ & Reactivity, $\mathrm{cm}^{3} /(\mathrm{g} \cdot \mathrm{s})$ & $\begin{array}{l}\text { Specific electrical } \\
\text { resistance } 10^{-6} \\
\mathrm{Ohm} \cdot \mathrm{m}\end{array}$ \\
\hline Pitch brand B & 758 & 59.6 & 1.39 & 1348 \\
\hline $\begin{array}{l}\text { Pitch modified with MBP, wt \% } \\
\qquad \begin{array}{c}2 \\
4 \\
6 \\
8\end{array}\end{array}$ & $\begin{array}{l}758 \\
758 \\
758 \\
755\end{array}$ & $\begin{array}{l}59.6 \\
59.6 \\
59.6 \\
60.2\end{array}$ & $\begin{array}{l}1.39 \\
1.35 \\
1.35 \\
1.37\end{array}$ & $\begin{array}{l}1347 \\
1345 \\
1345 \\
1346\end{array}$ \\
\hline $\begin{array}{l}\text { Pitch modified with LBP, wt \% } \\
2 \\
4 \\
6 \\
8\end{array}$ & $\begin{array}{l}758 \\
780 \\
784 \\
788\end{array}$ & $\begin{array}{l}59.6 \\
59.4 \\
59.0 \\
59.0\end{array}$ & $\begin{array}{l}1.40 \\
1.42 \\
1.44 \\
1.50\end{array}$ & $\begin{array}{l}1350 \\
1360 \\
1390 \\
1398\end{array}$ \\
\hline $\begin{array}{l}\text { Pitch modified with CCP, wt \% } \\
2 \\
4 \\
6 \\
8\end{array}$ & $\begin{array}{l}758 \\
750 \\
750 \\
748\end{array}$ & $\begin{array}{l}59.6 \\
59.5 \\
59.3 \\
59.0\end{array}$ & $\begin{array}{l}1.40 \\
1.40 \\
1.45 \\
1.50\end{array}$ & $\begin{array}{l}1349 \\
1350 \\
1355 \\
1359\end{array}$ \\
\hline
\end{tabular}

The study of the dynamics of changes in the properties of pitch with the use of LBP in the amount of 2$4 \mathrm{wt} \%$ shows that the presence of electrode pitches of different functional groups greatly affects the rate of thermochemical transformations of carbonation processes. The mechanism of compaction reactions changes, which is reflected in the properties of intermolecular interactions, is caused by an increase in the surface activity of coke to 1.40 $1.50 \mathrm{~cm}^{3} /(\mathrm{g} \cdot \mathrm{s})$ and a decrease in its density to $748 \mathrm{~kg} / \mathrm{m}^{3}$.

\section{Conclusions}

As a result of the conducted researches it was established that the formation of graphitosomal structures in the carbonization process of pitch modified with additives is characterized by different influence of these substances on thermochemical processes, coalescence of graphitosomes and optical microstructure of coke residue. Modifiers can change the period of nucleation of graphitosomal fragments, the course of thermochemical transformations, which is reflected in the performance properties of the finished product. Therefore, using one or another modifier in the amount of $2-6 \mathrm{wt} \%$, one can adjust the properties of the electrode pitch (carbon fiber size, porosity, resistivity, surface activity and density), which is very relevant today for carbon produced for electrode production. 


\section{References}

[1] Ball D.: Carbon, 1978, 3, 205. https://doi.org/10.1016/00086223(78)90025-8

[2] Sarkar A., Kocaefe D. et al.: Fuel, 2014, 117, 598. https://doi.org/10.1016/j.fuel.2013.09.015

[3] Marsh H., Mochida I., Scott E.: Fuel, 1980, 7, 517. https://doi.org/10.1016/0016-2361(80)90181-7

[4] Cheshko F., Skripchenko N. et al.: Coke Chem., 2014, 57, 255. https://doi.org/10.3103/S1068364X14060027

[5] Starovoyt A., Malyi E. et al.: Coke Chem., 2004, 6, 390.

[6] Sakawa M.: Fuel Soc. Jap., 1991, 70, 782. https://doi.org/10.3775/jie.70.8_782

[7] Starovoit A., Chemerinskii M., Malyi E., Chem. Chem. Technol., 2014, 8, 475. https://doi.org/10.23939/chcht08.04.475

[8] Starovoit A., Malyi E. Chem. Chem. Technol., 2008, $2,65$.

[9] Malyi E., Chemerinskii M. et al.: Chem. Chem. Technol., 2018, 12, 533. https://doi.org/10.23939/chcht12.04.533

[10] Malyi E., Chemerinskii M. et al.: Coke Chem., 2018, 61, 392. https://doi.org/10.3103/S1068364X18100058

[11] Malyi E., Chemerinskii M. et al.: Coke Chem., 2017, 60, 37. https://doi.org/10.3103/S1068364X17010069

[12] Pyshyev S., Grytsenko Y. et al.: Petrol. Coal, 2015, 57, 303.
[13] Pysh'yev S., Gunka V. et al.: J. Fuel Chem. Technol., 2012, 40, 129. https://doi.org/10.1016/S1872-5813(12)60009-7

[14] Starovoit M.: Chem. Chem. Technol., 2019, 1, 107. https://doi.org/10.23939/chcht13.01.107

Received: July 17, 2020 / Revised: August 06, 2020 / Accepted: December 22, 2020

\section{МОДИФІКАЦІЯ ЕКСПЛУАТАЦЙНИХ ВЛАСТИВОСТЕЙ ЕЛЕКТРОДНИХ ПЕКІВ}

Анотація. Досліджено вплив типу вуглецевого модифікатору та температури модифікаиіі на прочеси карбонізації електродного пеку та вуглецевих мас при вуглецевому виробництві. Вказані прочеси, щзо відбуваються при карбонізаиії електродного пеку та досліджено його властивості в прочесі модифікачії. Показано, щуо найбільш перспективним додатком є середньокипляча полімерна суміш, яка сприяє карбонізації пеку та покращанню фізико-хімічних властивостей.

Ключові слова: карбонізація, електродний пек, вуглецева маса, графітосомні надмолекулярні структури. 